\title{
Discussão de tópicos de Matemática Básica nos espaços sociais da Web 2.0: desafios e possibilidades a partir da análise de uma intervenção pedagógica
}

Simone Leal Schwertl

$\frac{\text { sileal@furb.br }}{0000-0002-8693-4220}$

Universidade Regional de Blumenau,

Blumenau, Santa Catarina, Brasil.

\section{André Ary Leonel}

\section{RESUMO}

O presente artigo apresenta a análise de uma intervenção pedagógica centrada no apoio de espaços sociais da Web 2.0 para discussões de tópicos de Matemática Básica. Inicialmente apresentam-se os espaços sociais da Web 2.0 como ambiente de possibilidades com vistas ao processo de ensino-aprendizagem. Na sequência, descrevem-se os objetivos e o caminho delineado para a inserção dos espaços sociais virtuais junto a uma disciplina. Por último, são apresentados os resultados da intervenção pedagógica por meio de uma análise críticoreflexiva orientada por duas categorias: (i) receptividade do uso de um blog e de um grupo do Facebook pelos alunos para a discussão de tópicos de matemática básica, e (ii) papel do professor em espaços sociais da Web 2.0. Quanto aos resultados obtidos, destaca-se que, às mediações pedagógicas e à colaboração entre os estudantes e o professor, foram identificados desafios que perpassam por transformações na relação professor-aluno historicamente marcada pela questão hierárquica.
\end{abstract}

PALAVRAS-CHAVE : Matemática Básica. Web 2.0. Educação. Colaboração. 


\section{INTRODUÇÃO}

O debate nas instituições de ensino para a inserção das Tecnologias Digitais da Informação e Comunicação (TDIC), além de ser compreendido como um dos efeitos da globalização no processo educativo, tem motivado diversas pesquisas na área da educação. Não há como negar que as mudanças provocadas por essas tecnologias, quanto aos modos de pensar, trabalhar e comunicar-se (PRETTO, 2005; ALONSO, 2008; LAPA, 2010; ALMEIDA e SILVA, 2011; MORAN, 2012), criam uma nova cultura, que pode ser entendida como cultura digital ou cibercultura, proporcionando um novo espaço comunicacional. Nela, não é preciso encontros e multidões, mas conexões e fluxos de rede, em que emergem novas formas de convivência e outros dispositivos de percepção (BARBEIRO, 2014).

No que tange à cibercultura, é importante pontuar as reflexões das três linhas de pensamento identificadas nos estudos de Rüdiger (2011), em que a cibercultura é entendida como um amplo processo de construção social da realidade, colocado em marcha no trilho das novas tecnologias. A primeira linha de pensamento apontada pelo autor diz respeito aos conservadores midiáticos que se negam a experimentá-las e, por consequência, "demonizam" as novas práticas que se desenham nos processos comunicacionais contemporâneos - são os chamados tecnófobos. Pensando na educação, seriam aqueles sujeitos que negam todas as contribuições da cibercultura no contexto educacional, pois só the vinculam desvantagens. A segunda refere-se aos tecnófilos, pessoas que "veem somente o que as tecnologias podem fazer, mas não conseguem imaginar o que elas irão desfazer" (POSTMAN, 1993, p.1). Enquadram-se aqui os sujeitos que, de forma ingênua, só percebem vantagens na cibercultura e, a partir de um certo determinismo tecnológico, acreditam que essas tecnologias vieram para resolver todos os problemas. Já na terceira linha, Rüdiger (2011) descreve os cibercriticistas como aqueles que buscam identificar potencialidades, problemas e desafios que os sujeitos sociais enfrentam na atualidade diante da popularização das TDIC e que, por sua vez, tomam uma posição crítica sobre os novos aspectos que delas procedem.

Na direção de uma perspectiva cibercriticista, é relevante lembrar que o primeiro e principal motivo sobre o impacto das TDIC na educação, em geral, guarda relação com o papel dessas tecnologias na sociedade da informação, uma vez que o atual cenário político, social, econômico e cultural da sociedade contemporânea toma a educação e a informação como as vias principais para adquirir o que se tornou, nessa conjuntura, a mercadoria mais valiosa - o conhecimento. (ALONSO, 2008; COLL e MONEREO, 2010).

Nessa perspectiva, o objetivo de construir uma economia baseada no conhecimento coloca a aprendizagem em primeiro plano na educação escolar, o que significa trazer para a educação uma nova dimensão - a de motor fundamental para o desenvolvimento social e econômico. Assim, são agregadas à educação outras funções, para além da promoção do desenvolvimento, da socialização e da enculturação da identidade nacional ou de seu papel como meio para a construção da cidadania (MOREIRA e KRAMER, 2007).

Além disso, a centralidade crescente da educação e da informação na sociedade contemporânea veio acompanhada por um protagonismo, também crescente, das TDIC nos processos educacionais e formativos. Isso porque, em uma sociedade onde a construção de uma economia é baseada em conhecimento e 
que, portanto, coloca a aprendizagem em destaque no plano individual e social, as TDIC apresentam-se como poderosos instrumentos para promover aprendizagem tanto do ponto de vista qualitativo como quantitativo (MORAN, 2012), fato que reforça o potencial acenado pelas TDIC nos processos educativos e que deve ser seriamente considerado.

Moran (2012), ao considerar a inclusão da tecnologia na educação escolar, discorre a respeito de três fases: na primeira, as tecnologias são utilizadas para melhorar o que já se vinha fazendo, para automatizar processos e diminuir custos; na segunda, as tecnologias são inseridas parcialmente no projeto educacional das instituições de ensino, ou seja, cria-se uma página na internet com algumas ferramentas de pesquisa e comunicação, divulgam-se textos e endereços interessantes, desenvolvem-se alguns projetos bem como atividades no laboratório de informática, mas mantêm-se intocadas a estrutura das aulas, as disciplinas e os horários. Na terceira fase, observa-se um amadurecimento da implantação e do avanço da integração das tecnologias; nela, as instituições de ensino repensam o seu projeto político pedagógico e o seu plano estratégico, inserindo mudanças significativas que permitem a flexibilização parcial do currículo, com atividades digitais combinadas às presenciais. Assim, compreendese que, com as TDIC, os alunos passam a ter em mãos inúmeras possibilidades de pesquisa, comunicação e publicação, dentro e fora da escola (MORAN, 2012).

Todavia, para não correr o risco de continuar fazendo a velha educação com uma nova tecnologia, torna-se importante que as instituições de ensino analisem os recursos disponíveis nas atuais TDIC, para entendê-los e utilizá-los com critérios bem definidos. Não por conta de um modismo como tantos outros já vividos, mas porque os recursos da fase 2.0 da cibercultura, em especial os recursos dos espaços sociais da Web 2.0 (blogs, redes sociais, wikis, entre outros), parecem nos colocar diante de algo que há tempo é almejado por muitos educadores: um processo educativo centrado no estudante, que valorize sobretudo a sua condição de aprendiz e a possibilidade de construção coletiva do conhecimento.

Surge, dessa forma, um cenário de possibilidades no que se refere à inovação das práticas docentes, ao mesmo tempo em que se percebe que transformar não é uma tarefa fácil, mas, sim, nas palavras de Demo (2010, p. 866), "um verdadeiro dilema". No que concerne a essa questão e, ao tomar como pano de fundo a obra de Christensem (2002) sobre o "dilema do inovador", Demo (2010) aponta a urgência de rupturas na educação, em particular diante dos recursos tecnológicos. Este autor ressalta que, apesar do atual contexto tecnológico sinalizar para possibilidades de inovações disruptivas - aquelas que rompem com dinâmicas vigentes e acenam para alternativas radicais -, a escola "tende a encolher-se em seus usos e costumes" (DEMO, 2010, p. 866).

Neste contexto, um exemplo a ser citado é a lousa digital. Um aparato tecnológico que, apesar de seus recursos interativos, ainda é usado, quando usado, na maioria das vezes para facilitar que o aluno copie ou mesmo grave a aula para seu computador com facilidade, ou seja, mais um material (sub)utilizado para sustentar práticas tradicionais de aula. $\mathrm{O}$ mesmo pode ser percebido na educação a distância, que, por vezes, recorre aos recursos digitais para aperfeiçoar a aula, para facilitar a transmissão de conteúdo ou ainda como fator motivacional. Exemplos que demonstram a continuidade do "instrucionismo" (DEMO, 2010), agora inserido no mundo digital. 
Como já mencionado, com o avanço das TDIC estamos vivendo a fase 2.0 da cibercultura, já com vistas à Web $3.0 \mathrm{com}$ a libertação do computador das conexões fixas a uma estação de trabalho que se estende para dispositivos móveis a exemplo dos celulares inteligentes - os smartphones. Estes, associados à evolução da internet sem fio, a exemplo das tecnologias wi-fi, 3G, 4G, têm possibilitado cada vez mais a mobilidade ubíqua, ou seja, o ciberespaço em comunicação com as cidades e estas com o ciberespaço (SANTOS, 2014).

Os novos artefatos digitais, por meio de seus dispositivos móveis, além de potencializarem a mobilidade, contam com a convergência de interfaces de várias linguagens que permitem editar, produzir e compartilhar em rede textos, imagens, sons de forma estática e dinâmica. No cenário nacional, merecem destaque os telefones celulares com acesso à internet, uma vez que existem cerca de 140 milhões de aparelhos ativos, dos quais $81 \%$ são comercializados por planos prépagos, segundo dados da ANATEL. Esse modelo de pagamento tem sido responsável pela popularização em massa da comunicação wireless no país (PELLANDA, 2009).

De outra parte, com o advento da Web 2.0, quando os blogs e as redes sociais (Facebook, YouTube, Twitter, Wiki etc.) mobilizam maior participação e autoria social, emerge um potencial de colaboração e compartilhamento por parte dos internautas no ciberespaço. Igualmente, configuram-se possibilidades de ampliação dos espaços de interação entre os participantes da cibercultura (PRIMO, 2006).

Segundo O'Reilly \& Battle (2009), um dos objetivos mais significativos da Web 2.0 passa pelo desenvolvimento de aplicativos que aproveitam os efeitos da rede para se tornarem melhores quanto mais forem usados pelas pessoas, de forma a beneficiar a inteligência coletiva. Portanto, em síntese, definir a Web 2.0 é ter como referência um conjunto de tecnologias associadas, tais como: blogs, podcasts, wikis, dentre outros, que promovem a conexão da sociedade com a Web e, sobretudo, se constituem como espaços em que todos são capazes de editar e publicar informações (ANDERSON, 2007).

Sendo assim, é sobre a perspectiva de conectar as instituições de ensino à Web 2.0 que se refere este trabalho, uma vez que, a partir do item a seguir, serão descritos aspectos de uma intervenção pedagógica pautada na discussão de tópicos de Matemática Básica para espaços sociais da Web 2.0, habitat da geração jovem na sociedade contemporânea.

Tem-se como pano de fundo a consciência de que a inserção de TDIC na educação remete a processos de inovação e equilíbrio, que demandam reflexões sobre a mudança que se configura, com vistas a evitar o risco real de que o fosso comunicativo-cultural entre as gerações e as instituições de ensino se torne intransponível.

\section{A intervenção pedagógica}

A intervenção pedagógica, iniciada em março de 2014 e finalizada em junho do mesmo ano, foi realizada junto à disciplina de Módulos de Matemática Básica, que tem como objetivo proporcionar aos acadêmicos de engenharia uma revisão 
dos encontros presenciais com o professor da disciplina, os acadêmicos contam com o auxílio de quatro monitores do Departamento de Matemática, no contraturno de seus cursos. Contudo, por conta dos sete cursos de engenharia da FURB terem turnos bem definidos, ou seja, matutino, vespertino ou noturno, a maioria dos alunos trabalha no contraturno e isso dificulta a procura pelos monitores.

No período supracitado, buscou-se uma estratégia didática que permitisse o domínio e a familiarização dos recursos dos espaços sociais da Web 2.0 principalmente por parte do professor. Feita a opção pelo uso de um blog e de um grupo fechado no Facebook, acrescentou-se, nesta busca, o interesse em investigar se aconteceria a colaboração entre os acadêmicos, nesses espaços sociais virtuais, no que tange aos debates de tópicos de Matemática Básica neles fomentados. Diante da afirmativa dessa colaboração, analisar possibilidades de promover a dialogicidade tradutora (DELIZOICOV, ANGOTTI e PERNAMBUCO, 2011), ou seja, um diálogo em que o professor, por meio da identificação e apreensão do conhecimento que o aluno detém, passa a problematizá-lo, aguçando as contradições e localizando as limitações desse conhecimento quando cotejado pelo conhecimento científico (propriedades e conceitos matemáticos), instigando-lhe a compreensão e a apropriação.

Tomou-se como horizonte o entendimento de que, num processo de colaboração, os membros de um grupo se apoiam, visando atingir objetivos negociados no coletivo, estabelecendo relações que tendem à não hierarquização e à confiança mútua (DAMIANI, 2008). Sendo assim, em oito turmas da disciplina de Módulos de Matemática Básica do primeiro semestre de 2014, foi socializada com os 250 alunos matriculados a criação do blog fechado: Desafios-Engenharia e do grupo fechado no Facebook: Engenharia primeiros desafios como suporte para discussões de tópicos de Matemática Básica. O termo "desafio" veio do entendimento de que passar na prova de Matemática Básica é um dos primeiros desafios que os alunos enfrentam nos cursos de engenharia da FURB.

Com vistas a estabelecer relações menos hierarquizadas e pautadas na construção de laços de confiança mútuos, a participação tanto no blog como no grupo do Facebook não era obrigatória e não estava vinculada a nenhum tipo de avaliação. Cabe ressaltar que a confiança é uma característica que alicerça interações em redes sociais e faz com que os sujeitos se tornem cada vez mais companheiros na execução de seus objetivos (PRIMO, 2008; CASTELLS, 2013).

No caso do blog, 250 (duzentos e cinquenta) alunos da disciplina Módulos de Matemática Básica foram convidados para serem "autores" e não apenas "leitores" do blog. A ideia foi abrir possibilidades para que os não usuários do Facebook também pudessem ou tivessem oportunidade de socializar suas dúvidas num espaço social da Web 2.0, sem necessariamente terem que participar de uma rede social. Não obrigar que os alunos tenham um perfil em uma rede social, mesmo os universitários, é um cuidado necessário ao associar espaços sociais da Web 2.0 junto a processos de ensino-aprendizagem formais ou institucionais. Dessa forma, a opção pelo uso de um blog tem se mostrado como uma possibilidade interessante.

Para provocar uma discussão crítica de tópicos de Matemática Básica, as postagens efetuadas pela professora tanto no blog como no grupo do Facebook, fundamentaram-se na teoria de Pontes (2013) sobre investigações matemáticas 
em sala de aula e na problematização de erros de Matemática abordada por CURY (2004). No entendimento de Pontes (2013), investigar não significa necessariamente lidar com problemas muito sofisticados, mas sim trabalhar com questões que nos interpelam e que se apresentam de modo confuso, mas que procuramos clarificar e estudar de modo organizado. No caso específico da Matemática, investigar assume características próprias que conduzem à formulação de conjecturas que se procuram testar e provar, se for o caso (PONTES, 2013). Em confluência com esse entendimento, postagens foram realizadas pela professora responsável tanto no blog como no Facebook solicitando análises do tipo:

- Que conhecimentos de Matemática Básica seriam necessários para resolver essa questão? - Como verificar se a resolução apresentada está correta ou não? Onde aconteceu o erro na resolução apresentada? - Que propriedade ou conceito de Matemática não foi verificado na solução apresentada?

Tais questionamentos, em sua maioria, foram realizados a partir de questões retiradas das provas aplicadas na disciplina Módulos de Matemática Básica, bem como das resoluções apresentadas pelos alunos.

Portanto, a intervenção pedagógica realizada tanto no blog, quanto no grupo fechado do Facebook, ancorou-se em instigar a investigação de erros provenientes das resoluções dos alunos e na problematização de conceitos e propriedades matemáticas para provocar discussões nos espaços virtuais que pudessem contribuir para a revisão de Matemática Básica. A análise de erros em Matemática é tomada como abordagem de pesquisa em Educação Matemática desde o início do século XX nos Estados Unidos e na Europa. Segundo dados de pesquisas realizadas no ensino superior, tal análise pode contribuir para esclarecer problemas de aprendizagem da Matemática (CURY, 2004).

No próximo tópico, serão apresentados alguns dos resultados obtidos com a intervenção pedagógica planejada.

\section{Resultados}

Por compreender a dificuldade para se estabelecer relações causais mais ou menos diretas entre a utilização das TDIC e a melhora na aprendizagem (COLL e MONEREO, 2010), os resultados da intervenção pedagógica foram organizados e analisados a partir da investigação de como se deu a apropriação dos espaços sociais da Web 2.0 (blog fechado e grupo fechado do Facebook) pelos participantes (professor e alunos) em um processo de ensino/aprendizagem e de como se configurou o processo de colaboração entre os participantes, incluindo o professor. Para tanto, organizaram-se a apresentação dos resultados e as análises em dois pontos: quanto à receptividade do uso do blog e do Facebook pelos alunos para a discussão de questões de Matemática Básica e quanto ao papel do professor nos espaços sociais da Web 2.0.

\subsection{Receptividade do uso do blog e do Facebook pelos alunos}

Uma das preocupações na implementação da intervenção pedagógica junto ao blog e ao grupo fechado do Facebook foi quanto à receptividade da proposta 
pelos alunos. Para analisar a receptividade dos espaços sociais da WEB 2.0 como suporte para a disciplina "Módulos de Matemática Básica", foi aplicado um questionário aos 250 alunos matriculados. Parte dos dados está organizada na Tabela 1 a seguir.

Tabela 1: Receptividade dos alunos quanto à utilização do Facebook para discutir questões de ensino/aprendizagem de Matemática Básica

\begin{tabular}{|l|c|}
\hline \multicolumn{1}{|c|}{ O que achou da iniciativa ? } & Alunos (\%) \\
\hline Não se manifestou & $52 \%$ \\
\hline Iniciativa muito positiva & $46,5 \%$ \\
\hline Não concorda com o uso do Facebook para o ensino & $1,5 \%$ \\
\hline Acessou o grupo do Facebook? & Alunos (\%) \\
\hline Sim & $14,7 \%$ \\
\hline Não & $56 \%$ \\
\hline Não respondeu a questão & $29,3 \%$ \\
\hline
\end{tabular}

Fonte: organizado pelos autores

A partir dos dados organizados na Tabela 1, é possível aferir que $46,5 \%$ dos alunos apreciaram, de certa forma, a iniciativa de usar o Facebook para discussão de Matemática Básica. Apenas 1,5\% dos alunos não concordaram com o uso do Facebook como apoio para a disciplina Módulos de Matemática Básica. Chama atenção, porém, o fato de apenas $14,7 \%$ terem acessado o grupo fechado Engenharia Primeiros Desafios, uma vez que somente $6,6 \%$ dos alunos afirmaram não serem usuários dessa rede social.

Os alunos também foram questionados quanto às razões para o não acesso ao Facebook. As questões eram abertas e os percentuais de respostas mais significativos se referem ao fato de $26 \%$ dos alunos relatarem não ter precisado do acesso ao grupo para solucionar suas dúvidas, $10 \%$ alegou preferir o material impresso para realizar seus estudos e, por mais que tivesse sido avisado em sala e por e-mail, 30\% dos alunos alegaram desconhecimento da criação do blog e do grupo no Facebook.

Diante desses percentuais, cabe ressaltar que o trabalho de revisão de Matemática Básica é um trabalho árduo. Ministrar aulas de Matemática Básica (tópicos de quinto ao nono ano do Ensino Fundamental) para calouros de engenharia apresenta o desafio da desmotivação dos alunos, o que leva a grandes índices de reprovação na disciplina Módulos de Matemática Básica, mesmo que ela seja pré-requisito de disciplinas da segunda fase dos cursos de engenharia. Diante desse contexto, levar a Matemática para os espaços sociais da Web 2.0 era a princípio "uma outra forma de estar junto" (BARBERO, 2014, p. 134) dos alunos e fazer com que as discussões da disciplina, no que se refere aos erros de Matemática Básica, estivessem conectadas ao habitat dos nativos digitais. Barbero (2014) enfatiza que o mundo ao qual a cibercultura trouxe mudanças visíveis e desconcertantes é o mundo dos jovens "cuja empatia com as linguagens audiovisuais e digitais é feita de uma cumplicidade expressiva" (BARBERO, 2014, p.134).

Cabe explicitar que, de certa forma, na intervenção pedagógica, não foi realizado um trabalho efetivo em sala de aula, ou seja, nos encontros presenciais, para incentivar/mobilizar os estudantes a usarem os espaços sociais da Web 2.0. 
Explicando melhor, a professora responsável pela disciplina divulgou a abertura do blog e do grupo do Facebook e, como já informado, a participação era de escolha do aluno e não valia nenhum tipo de nota. A ideia era verificar o uso "genuíno" que os estudantes fariam da possibilidade de ampliar o espaço de discussão de tópicos da disciplina Módulos de Matemática Básica, cujos encontros aconteciam apenas uma vez por semana e com duração de duas horas/aula (50 minutos cada hora/aula).

Nesse ínterim, dentre as razões apontadas pelos alunos para o acesso ao grupo do Facebook, chama a atenção o fato de $75 \%$, dos $14,6 \%$ dos alunos, que acessaram o Facebook, alegarem terem acompanhado as postagens na tentativa de solucionar suas dúvidas e apenas $10 \%$ afirmarem terem postado suas dúvidas e conseguido ajuda dos colegas para resolvê-las. Contudo, os $10 \%$ que postaram suas dúvidas, somados aos poucos que participaram respondendo às provocações realizadas pela professora no Facebook, foram os grandes colaboradores, uma vez que permitiram que as discussões acontecessem, de modo a serem observadas e analisadas pelos alunos que acompanharam as postagens (75\%, dos $14,6 \%$ dos alunos que acessaram o Facebook).

No caso do blog, a proposta não teve êxito, $80 \%$ dos alunos que responderam ao questionário alegaram não ter consultado o blog. Havia uma expectativa de que os alunos, de forma geral, usassem o blog e/ou o grupo do Facebook para socializar com os amigos e com o professor suas dúvidas de Matemática Básica. Como já mencionado, no caso do Facebook, apenas $10 \%$ dos alunos fizeram postagens no grupo socializando suas dúvidas e, no caso do blog, nenhuma postagem foi realizada pelos alunos.

O questionário aplicado também procurou identificar por que os alunos que acessaram o blog não fizeram nenhuma postagem. As respostas obtidas foram um tanto diversificadas, como é característica de uma questão aberta e as mais significativas foram organizadas na Tabela 2 a seguir.

Tabela 2: Por que os alunos não postaram no Blog - Desafios Engenharia?

\begin{tabular}{|l|r|}
\hline Respostas & Alunos (\%) \\
\hline Não se posicionou & $56 \%$ \\
\hline Falta de interesse & $36 \%$ \\
\hline Vergonha da exposição & $21 \%$ \\
\hline Falta de tempo & $13 \%$ \\
\hline Medo de errar & $12,5 \%$ \\
\hline O presencial ou material impresso foi suficiente & $7 \%$ \\
\hline É só uma questão de tempo e adaptação & $6,5 \%$ \\
\hline Não tem dúvidas & $6 \%$ \\
\hline Não é dinâmico & $4 \%$ \\
\hline Prefere recorrer a um colega ou a sites de pesquisa & $4 \%$ \\
\hline Porque os blogs não são mais usados & $3 \%$ \\
\hline O aluno quer informação e não postar & $2 \%$ \\
\hline $\begin{array}{l}\text { Usam o blog mais para estudo, acompanhando as } \\
\text { postagens }\end{array}$ & $2 \%$ \\
\hline Porque o blog é administrado por um professor & $1 \%$ \\
\hline
\end{tabular}


Conforme dados da Tabela 2, chama a atenção que 12,5 \% dos alunos alegaram medo de errar, $21 \%$ vergonha da exposição, $13 \%$ falta de tempo. Um número significativo, $36 \%$ dos alunos, alegou falta de interesse em postar no blog. Esses percentuais sinalizam desafios para a intervenção pedagógica, ou seja, assim como nas aulas presenciais, a vergonha da exposição, o medo de errar, e a falta de interesse aparecem como fator limitador para a colaboração dos estudantes nos espaços sociais da Web 2.0.

Quanto à colaboração nos espaços sociais da Web 2.0 - a qual pode ser realizada por meio de postagens e comentários em que os indivíduos estabelecem uma forma de diálogo sobre determinada temática - cabe lembrar as postulações de Freire (1982), quando o autor defende que o diálogo, ao fundamentar-se no amor, na humildade e na fé nos homens, estabelece uma relação horizontal em que a confiança de um polo ao outro - e que se faz colaboração - é uma consequência evidente (FREIRE, 1982). Freire enfatiza que a confiança de um polo ao outro faz os sujeitos mais companheiros na pronúncia do mundo e, se essa confiança falha, é porque falharam as condições supracitadas. De outra parte, no que concerne à confiança nos espaços sociais da Web 2.0, estudos como os de Costa (2008) advogam que, para que redes sociais sejam construídas, elas devem ter como base a confiança mútua disseminada entre os indivíduos da forma mais ampla possível.

No contexto escolar, as postulações de Freire e Costa remetem ao fato de que existe uma relação de poder entre professor/aluno marcada por questões avaliativas e que é preciso promover ou ainda renovar a cultura de confiança/colaboração entre professor e aluno para a construção de conhecimento em tempos de cibercultura, ou ainda, para a reconstrução de conhecimento, como é o caso da revisão de Matemática Básica, cuja experiência tem demonstrado que não se trata apenas de relembrar conceitos e propriedades, mas, muitas vezes, de reconstruir apropriações matemáticas equivocadas.

Entende-se que, no contexto de intervenções pedagógicas, parafraseando Freire (1982) - a confiança que se faz colaboração -, existe o desafio da questão avaliativa que marca a relação professor/aluno principalmente no que se refere à exposição de erros e dificuldades, ou mesmo de conhecimentos sobre determinado assunto. Nesse processo, o resultado da avaliação, da aprovação, passa a ser mais importante do que a verdadeira construção de conhecimento. Por conseguinte, não se pode descartar a hipótese de que, diante da presença do professor da disciplina no grupo do Facebook, os alunos não tenham exposto suas dificuldades com receio de como elas poderiam ser utilizadas num contexto avaliativo ou, ainda, por vergonha em explicitar suas dificuldades perante os colegas. Nessa perspectiva, embora esse comportamento seja recorrente nas aulas presenciais, parece que, num ambiente virtual, o fato de deixar o registro por escrito pode ganhar maior relevância e produzir certo bloqueio ou desconforto.

Não obstante, essas situações podem ser superadas com duas medidas conjuntas: a prática dialógica e a ressignificação do papel do erro. Enquanto a primeira contribui para a construção de laços de confiança e de colaboração que promovem a troca de experiências por meio do diálogo entre conhecimentos e o enfrentamento dos erros, a segunda pode levar os alunos a agirem com maior naturalidade diante dos erros, a perderem o medo de arriscar e, sobretudo, perceberem a sua importância no processo de ensino-aprendizagem. 
Contudo, apesar dos baixos percentuais de participação dos estudantes, a análise realizada permite afirmar que as "colaborações dos alunos" que ocorreram no grupo fechado do Facebook se resumiram em: compartilhamento de dúvidas, de conhecimentos sobre o assunto e de pontos de vistas sobre a questão abordada ou sobre o conceito matemático envolvido. De certa forma, entende-se que essa exposição no grupo do Facebook demonstra, por parte dos estudantes: "confiança" em si mesmos, ao expor suas dúvidas ou ao ajudar o colega com seus conhecimentos, além de confiança na proposta pedagógica e no companheirismo dos seus pares (SCHWERTL, 2016).

Os dados aqui apresentados permitem concluir que a imbricada relação entre confiança e colaboração, pontuada anteriormente, sobretudo entre professoraluno, ao mesmo tempo em que se coloca como um horizonte para intervenções pedagógicas nos espaços sociais da Web 2.0, apresenta-se igualmente como um desafio para a relação professor-aluno historicamente construída.

Nesse sentido, entende-se, tanto como necessidade, quanto como desafio, a necessidade de construção de uma imbricada relação de confiança/colaboração quando se almeja o apoio dos espaços sociais da Web 2.0 em intervenções pedagógicas para que, de fato, os sujeitos se tornem companheiros na pronúncia (ou leitura) crítica do mundo que os envolve.

\subsection{O papel do professor nos espaços sociais da WEB 2.0.}

Neste item, são apresentadas duas postagens da professora responsável pela disciplina Módulos de Matemática básica no grupo fechado do Facebook. Por meio delas, demonstram-se tanto o papel que um docente pode desempenhar em espaços sociais da Web 2.0, quanto a "colaboração" dos estudantes a partir das provocações presentes nas publicações, as quais consistem na elaboração de perguntas que os alunos não costumam fazer ao resolverem questões de Matemática Básica, o que faz com que o professor atue, na verdade, como mediador do diálogo que ocorre a partir das postagens ou ainda como um provocador para desencadear diálogos. O objetivo, em síntese, é problematizar as soluções apresentadas, na tentativa de contribuir para a melhor compreensão de propriedades e conceitos da área da Matemática Básica, conforme exemplificado nas Figuras 2a e $2 b$ a seguir.

Na Figura 2a, a professora posta uma questão de Matemática Básica cuja resolução está errada e, após comentários dos alunos, são mostradas as propriedades matemáticas que conduzirão à resolução correta da questão. $\mathrm{Na}$ mesma postagem, na continuidade do diálogo, um aluno aponta o caminho para a solução, fazendo menção a uma determinada propriedade necessária à resolução correta, que não foi observada. 


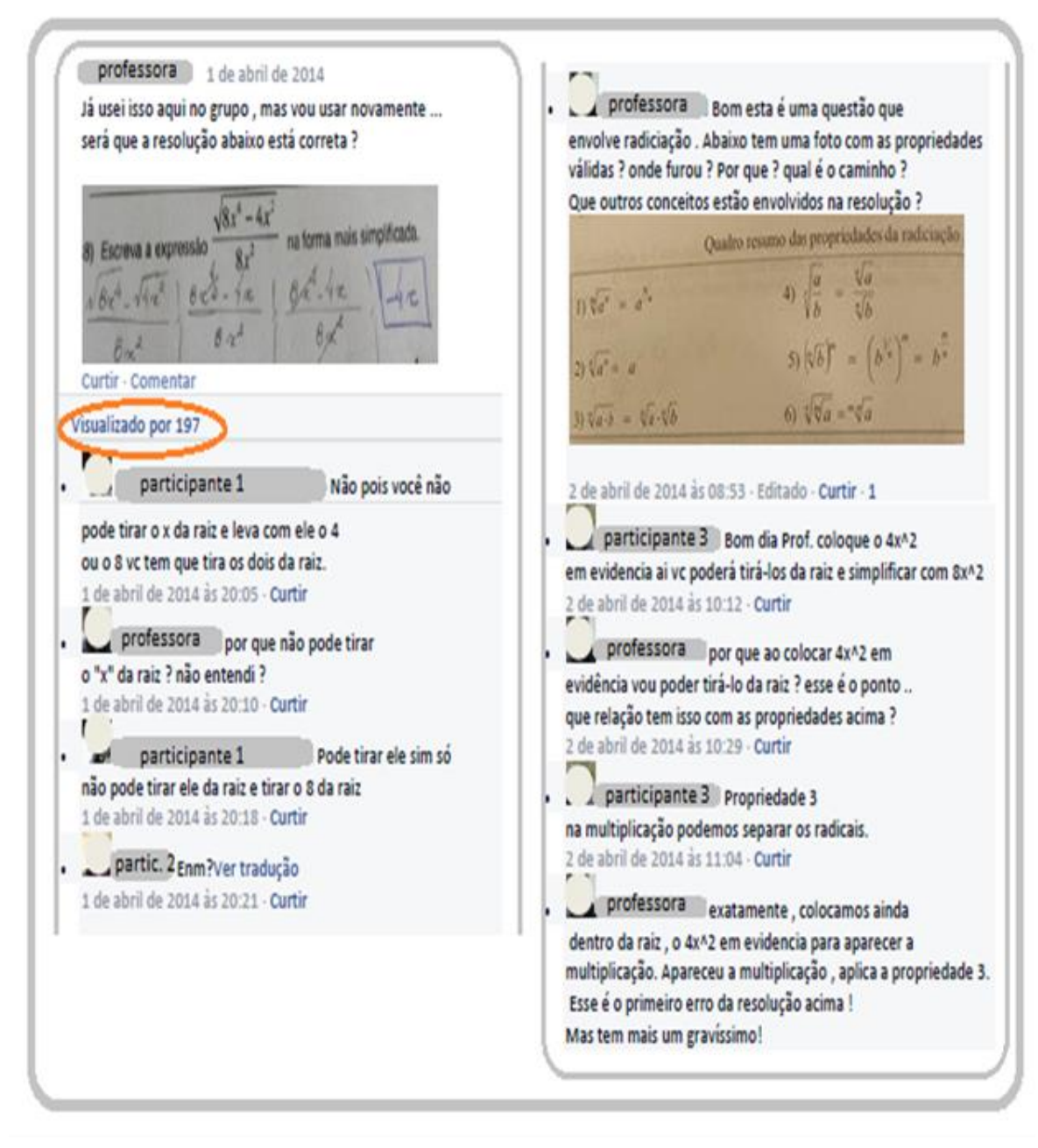

(Fonte: organizado pelos autores)

Na Figura 2b, é mostrada uma postagem no grupo do Facebook com uma questão de Matemática Básica com um erro de simplificação extremamente recorrente entre os alunos dos cursos de engenharia. 
Figura $2 \mathrm{~b}$ - Postagem do professor no grupo fechado do Facebook

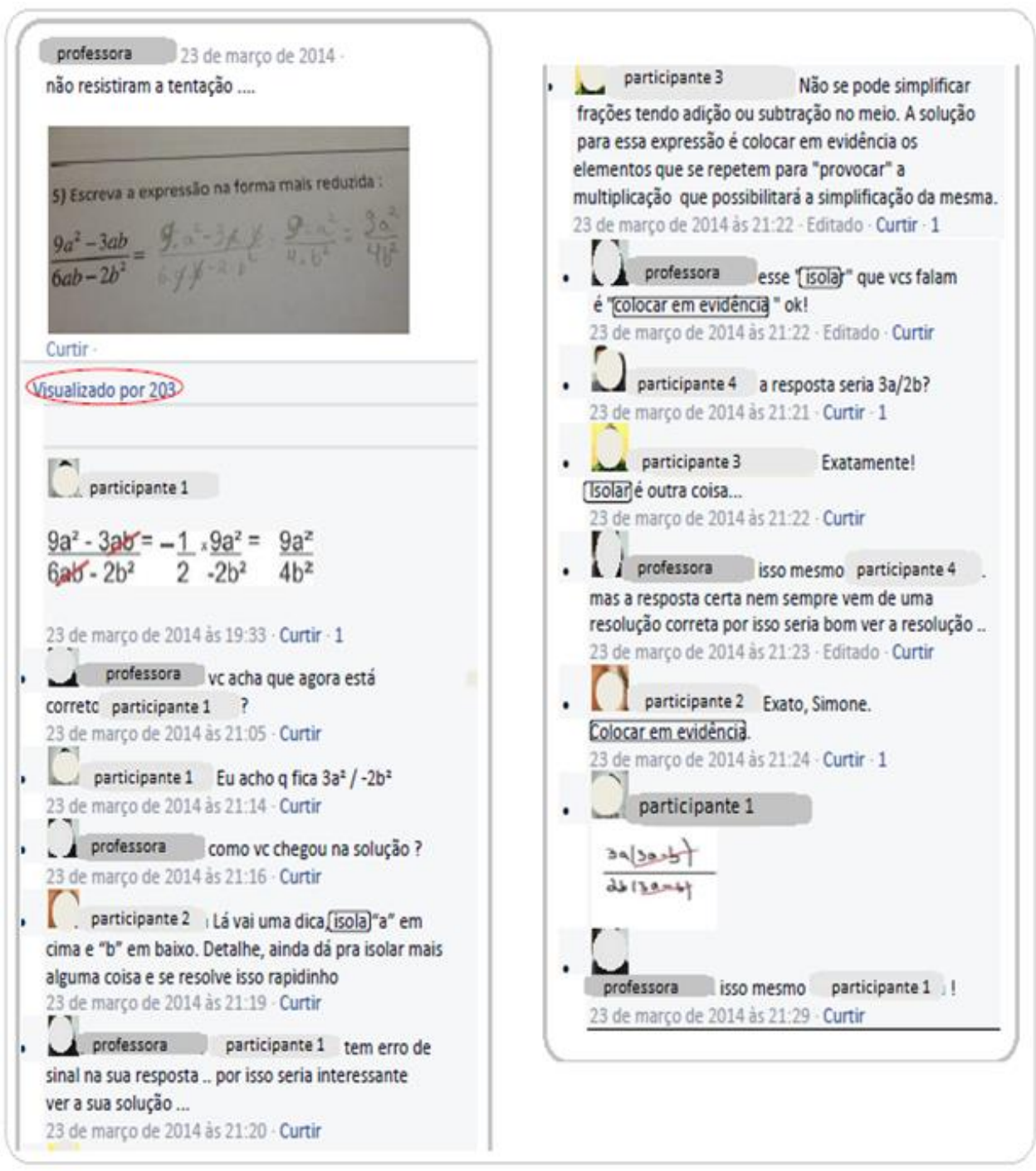

(Fonte: organizado pelos autores)

No diálogo decorrente da postagem da Figura $2 \mathrm{~b}$, é possível verificar que a professora tece questionamentos a partir das respostas apresentadas pelos alunos e estimula-os a socializarem as suas resoluções para que elas possam ser analisadas. Na sequência, um aluno apresenta, além da resposta, a resolução correta da questão. Destaca-se também, nessa postagem, a diferenciação realizada pela professora entre os termos "isolar" e "colocar em evidência", de forma a instigar os alunos a se apropriarem dos termos matemáticos de forma correta.

Por meio das discussões apresentadas nas Figuras $2 \mathrm{a}$ e $2 \mathrm{~b}$, demonstram-se traços de um "diálogo tradutor" (DELIZOICOV, ANGOTTI e PERNAMBUCO, 2011) almejado pela intervenção pedagógica nos espaços sociais da Web 2.0. Em especial, no exemplo da Figura 2a, quando a professora questiona onde ocorreu o 
erro na resolução apresentada, busca-se inicialmente proporcionar um distanciamento crítico do aluno acerca de seu conhecimento. Na continuidade, a partir da apresentação das propriedades matemáticas, almeja-se uma desestabilização das convicções dos alunos para a compreensão e aplicação das propriedades de Matemática Básica (conhecimento científico) para a resolução correta da questão.

O diálogo tradutor é uma das características fundamentais de um modelo didático-pedagógico que tem como eixo a problematização dos conhecimentos (DELIZOICOV, ANGOTTI e PERNAMBUCO, 2011). Nessa proposta, cabe ao professor identificar e formular problemas ou questionamentos a partir de situações vividas pelos alunos, com vistas a conduzir, por meio do diálogo entre os conhecimentos (do professor e do aluno), a conscientização e a necessidade da abordagem e apropriação de novos conhecimentos.

No caso da revisão de tópicos de Matemática Básica, tal estratégia torna-se pertinente, uma vez que os alunos muitas vezes se apropriaram de formas inadequadas de resolução que, quando problematizadas ou questionadas, podem promover a desestabilização de convicções equivocadas e a necessidade de apropriação correta de conceitos e propriedades da matemática. Ademais, cabe ressaltar que a problematização é um elemento extremamente importante para fomentar o diálogo e instigar a busca por novos conhecimentos - como pode ser visto nas intervenções realizadas pela professora nos diálogos decorrentes das postagens apresentadas nas figuras $2 \mathrm{a}$ e $2 \mathrm{~b}$ - configurando-se como elemento relevante a fim de que espaços sociais da Web 2.0, quando associados a intervenções pedagógicas, sejam dialógicos e colaborativos.

É fundamental destacar ainda que os diálogos realizados com a participação/mediação do professor, principalmente no grupo fechado do Facebook, ficaram registrados e os alunos puderam revisitá-los. Nesse sentido, os recursos dessa rede social, embora limitados, informam que a postagem da Figura 2a obteve 197 visualizações e a da Figura 2b, 203.

\section{CONSIDERAÇÕES FINAIS}

Numa primeira análise, os baixos percentuais de participação dos estudantes suscitam reflexões quanto ao potencial dos espaços sociais da Web 2.0 como ambientes motivacionais para o envolvimento dos alunos em processos de ensino/aprendizagem. Com efeito, os baixos percentuais de acesso remetem ao fato de que a tecnologia por si só, por mais inovadora, não tem o potencial de transformar a educação e motivar os alunos a se envolverem em processos de ensino e aprendizagem de conteúdos acadêmicos.

Contudo, os alunos que confiaram nos espaços sociais da Web 2.0 e tiveram coragem ou iniciativa para postar suas dúvidas e suas resoluções colaboraram com as discussões e possibilitaram que o diálogo, constituído no âmbito das postagens acerca de tópicos de Matemática Básica, pudesse ser observado por $75 \%$ dos $14,65 \%$ dos alunos que acessaram o grupo do Facebook.

Além disso, os estudantes favoráveis à proposta sugeriram que o grupo da disciplina Módulos de Matemática Básica fosse socializado com outros grupos do Facebook, específicos de cada curso de engenharia da instituição. Esse fato fez com que integrantes de outras fases, com a permissão dos alunos da disciplina Módulos 
de Matemática Básica, também fizessem parte do grupo. Diante dessa situação, algumas dúvidas postadas por alunos "calouros" foram respondidas, no grupo da disciplina Módulos de Matemática Básica, por "veteranos" ou por alunos que já tinham sido aprovados na disciplina, sem haver necessariamente a intervenção da professora.

De outra parte, foi possível que a professora observasse as contribuições dos alunos veteranos e pudesse intervir quando fosse necessário como exemplificado na postagem da Figura $2 b$, em que o diálogo ocorreu entre dois alunos calouros, dois alunos veteranos e a professora.

Como já mencionado, a disciplina Módulos de Matemática Básica tem como objetivo proporcionar uma revisão de conceitos e propriedades que são trabalhados do quinto ao nono ano do Ensino Fundamental. Quando chegam à disciplina, grande parte dos alunos apresenta muitas dificuldades, que foram adquiridas ao longo da formação básica, e alguns ainda trazem lembranças embaralhadas por "macetes" e "vícios" de resoluções equivocadas.

Nesse contexto, problematizar os erros, contrapondo os conceitos e propriedades que embasam a solução correta, mostra-se um caminho para revisar tópicos de Matemática Básica, primando por uma conscientização, para além da repetição mecânica de uma lista de exercícios, para muitos ainda necessária. É importante ressaltar que a maioria dos erros problematizados nas resoluções dos alunos são erros clássicos e recorrentes, cuja eliminação, em disciplinas básicas e específicas dos cursos de engenharia, tem sido um grande desafio para a Instituição.

No que tange à Matemática nos cursos de engenharia, a experiência docente permite afirmar que essa ciência tem, pelo menos, duas facetas bem definidas. Por um lado, ela é vista como um grande problema, pois altos índices de reprovações e desistências, nas primeiras fases dos cursos de engenharia, são, em sua maioria, advindos de problemas específicos de ensino-aprendizagem da matemática, principalmente no que se refere às questões mais abstratas e de ordem cognitiva. Além disso, a dificuldade de aprendizagem dessa disciplina no ensino médio é apontada como uma das fortes razões do afastamento dos jovens da engenharia (IEL, 2006). Noutra perspectiva, a matemática, uma ciência de linguagem universal, é tida como poderosa e de grande aplicação para o desenvolvimento científico e tecnológico, o que faz com que essa área seja tomada e reconhecida como prérequisito fundamental e valioso para uma formação de qualidade nos cursos em questão.

Diante desse cenário, o presente artigo sinaliza uma significativa contribuição dos espaços socais da Web 2.0 quando associados a intervenções pedagógicas voltadas para a área da Matemática, uma vez que, a partir dos recursos e interfaces dos dispositivos móveis, a exemplo dos celulares inteligentes - os smartphones os estudantes encontraram outras formas de utilizar e socializar a linguagem matemática, por meio de fotos ou outras imagens (ver Figura $2 b$ - comentários do participante 1), indo além das limitações do teclado tradicional de um computador que dificultam a escrita de símbolos matemáticos. As apropriações exemplificadas por meio das Figuras $2 \mathrm{a}$ e $2 \mathrm{~b}$ sinalizam possibilidades genuínas de se ampliar os espaços de discussões de tópicos de Matemática Básica, para além do tempo presencial da disciplina Módulos de Matemática Básica, bem como dão indícios de potencialidades de circulação desse conhecimento no habitat dos nativos digitais. 
No entanto, para que a discussão da Matemática Básica se torne cultura no cotidiano digital dos alunos dos cursos de engenharia, por meio dos espaços sociais da Web 2.0 dos quais os jovens fazem parte - a exemplo do Facebook - é imprescindível compreender que, mais do que trazer de forma "encapsulada a produção de conhecimento possível na Web para a escola ou pensar que ela, em si, poderia substituir a escola, seria buscar derrubar estes muros em práticas conjuntas e complementares" (LAPA, 2013, p.38). É consenso que a atual fase da cibercultura tem potencial para transformações na educação, as quais estão diretamente relacionadas à apropriação que os usuários farão dos recursos e interfaces disponíveis, capazes de gerar consequências positivas ou negativas.

Mediante essa compreensão, entende-se a relevância do papel do professor, que, como intelectual público e transformador (GIROUX, 1997, 2013), ao participar dos espaços sociais da Web 2.0, pode contribuir com a formação de uma visão mais crítica acerca desses espaços. Entretanto, para que isso ocorra, para além da busca por cativar os alunos por meio da Web, o docente precisa compreendê-la como uma nova cultura na qual as pessoas aprendem, pensam e interagem de uma forma diferente, uma cultura que não mais comporta a noção comunicativa clássica de emissor-receptor, mas a compreensão de que dela emergem novas lógicas, novas semânticas e novos conjuntos de habilidades e/ou competências construídas a partir do uso de diferentes tecnologias (PASSARELLI, JUNQUEIRA e ANGELUCI, 2014).

No que se refere ao trabalho docente, porém, é importante enfatizar e ressaltar que os espaços sociais da Web 2.0, associados aos dispositivos móveis, atravessam a vida das pessoas, invadem momentos de lazer, de convivência familiar e, sendo assim, para o professor que já é um profissional que leva o serviço para casa, é preciso vigilância, disciplina, planejamento, mas, sobretudo, apoio das Instituições de Ensino (IE).

Os professores só poderão encontrar rotas para enfrentar os novos e antigos desafios que se colocam para a educação na cibercultura, se as IE abrirem oportunidades para que os recursos disponíveis na Web 2.0 possam ser compreendidos e utilizados com critérios pedagógicos bem definidos, o que deve ocorrer não no sentido de excluir processos e metodologias, e sim na perspectiva de inclusão de novas interfaces (SANTOS, 2014). Esse movimento deve ocorrer tanto para melhorar o que já se tem feito, quanto principalmente para descobrir novos caminhos para a educação na sociedade agora interconectada. Isso não significa se render aos modismos tecnológicos, mas usar as TDIC a favor de uma educação de qualidade que, certamente, passa pelas concepções epistemológicas do professor que busca o apoio dos espaços sociais da Web 2.0 em intervenções pedagógicas.

Quanto ao apoio dos espaços sociais da Web 2.0 para a discussão de erros de Matemática Básica, a análise das "colaborações dos alunos", associada aos ensinamentos de Freire (1982) sobre o diálogo, permite inferir que (e isso o professor não pode esquecer) somente a ação verdadeira, transparente, humilde e pautada na fé nos homens poderá criar laços de confiança que se farão colaboração para que o diálogo entre os conhecimentos do professor e dos alunos aconteça nos espaços sociais da Web 2.0, com vistas à promoção de rupturas em apropriações equivocadas. Esse, portanto, é o desafio que se apresenta a professores e à educação escolar, que procuram o apoio dos espaços sociais da Web 2.0 junto a intervenções pedagógicas, bem como para pesquisadores que 
buscam desenvolver instrumentos de pesquisa capazes de identificar como se constitui ou o que deflagra a confiança que se faz colaboração nos espaços sociais da Web 2.0, associados a intervenções dessa natureza. 


\title{
Discussions of Basic Mathematics topics in Social Spaces of Web 2.0: chalenge and possibilits from analysis of one pedagogical intervention
}

\begin{abstract}
This article presents the analysis of a pedagogical intervention centered around the support provided by social spaces of Web 2.0 for discussions within topics of Basic Mathematics. In the first section, we present a theoretical review of the social spaces within Web 2.0 as a space of possibilities for education. Following this, we outline the goals and the path for the insertion of virtual social spaces along the subject. Lastly, we present the results of the pedagogical intervention through a critical reflexive analysis, guided by two categories: (i) receptiveness to the use of a blog and a group on Facebook by the students for the discussion of topics in Basic Mathematics, and (ii) the role of the teacher in social spaces of Web 2.0. The analyzed data were constituted by the posts and comments made within the virtual social spaces as well as though a survey answered by the students. Within the results to be highlighted, the pedagogical mediations and collaboration between the students and the teacher presented challenges that pass through transformations in the teacher-student relationship, historically marked by hierarchy issue.
\end{abstract}

KEYWORDS: Web 2.0. Education. Basic Mathematics. Collaboration. 


\section{REFERÊNCIAS}

ANDERSON, P. What is $\mathbf{2 . 0}$ ? Ideas, Technologies and implications for education. 2007. Disponível em: < http://www.jisc.ac.uk/media/documents/techwach/tsw0701b.pdf >. Acesso em: 17 nov. 2014.

ALMEIDA, M. E. B.; SILVA, M. G. M. Currículo, tecnologia e cultura digital: espaços e tempos de Web currículo. Revista e-Curriculum, São Paulo, v. 7, n.1, Abril, 2011. Disponível em:

$<$ http://revistas.pucsp.br/index.php/curriculum/article/viewFile/5676/4002>. Acesso em: 28 jul. 2014.

ALONSO, K. M. Tecnologias da informação de professores: sobre redes e escolas. Educação e Sociedade, Campinas, v. 29, n. 104, Especial, p. 747-768, out. 2008.

BARBERO, M. J. A comunicação na educação. Tradutoras LOPES, M. I. V. e MELO, D. São Paulo: Contexto, 2014.

CASTELLS, M. Redes de indignação e esperança: movimentos sociais na era da internet. Tradução MEDEIROS, C.A. 1 ${ }^{\text {a }}$. ed. Rio de Janeiro: Zahar, 2013.

CHRISTENSEN, C.M. Theinnvator's dilemma. Havard: Harper Collins Publishers, 2002.

COLL, C.; MONEREO, C. Psicologia da educação virtual: aprender e ensinar com as tecnologias da informação e da comunicação. Tradução FREITAS, N. Porto Alegre: Artmed, 2010. 365 p.

COSTA, da R. Por um conceito de comunidade; redes sociais, comunidades pessoais, inteligência coletiva. In: ANTOUN, H.Web 2.0: participação e vigilância na era da comunicação distribuída. Rio de janeiro: Manual X. p. 29-48, 2008. 
DELIZOICOV, D.; ANGOTTI, J. A.; PERNAMBUCO, M. M. Ensino de ciências: fundamentos e métodos. São Paulo: Cortez, 2011.

DEMO, P. Rupturas urgentes em educação. Ensaio: aval. pol. públ. Educ., Rio de Janeiro, v.18, n.69, p.861-872, out/dez. 2010.

FREIRE, P. Pedagogia do Oprimido. Rio de Janeiro: Paz e Terra, 1982.

GIROUX, H. A. Os professores como intelectuais: rumo a uma pedagogia crítica da aprendizagem. Tradução: Daniel Bueno. Porto Alegre: Artes Médicas, 1997.

GIROUX, H. La pedagogía crítica en tiempos oscusos. Praxis Educativa, n. 17/ 1 e 2, p 13-26, jan/dez 2013.

INSTITUTO EUVALDO LODI (IEL) Núcleo Nacional. Inova engenharias: propostas para a modernização da educação em engenharia no Brasil. Brasília: IEL.NC/SENAI. DN, 2006.103p.

LAPA, A. B.; BELLONI, M. L. Introdução à educação a distância. Florianópolis: UFSC/CED/NUP, 2010.

LAPA, A. Reflexões críticas sobre a formação em redes sociais. In: NERGMAN, J y GRANÉ, M. La universidad em la nuven. LMI, Col-lecció Transmedia XXI. Laboratori de Mitjans Interactius. Universidade de Barcelona. Barcelona, 2013.

LÉVY P. Cibercultura. Rio de Janeiro: 34 Letras, 1999.

MORAN, J. M. As novas tecnologias e o universo escolar. Revista A\&E. ano 13. $\mathrm{n}^{0} \cdot 20$, out. 2012.

O’REILLY, T.; BATTELLE, J. Web Squared: Web 2.0 Five Years On. 2009. Disponível em: <http://www.web2summit.com/web2009/public/schedule/detail/10194>. Acesso em: 10 nov. 2014.

MOREIRA, A. F. B.; KRAMER, S. Contemporaneidade, educação e tecnologia. Educação \& Sociedade, Campinas: v. 28, n. 100, p. 1037-1057 out 2007.

PASSARELLI, B.; JUNQUEIRA, A.; ANGELUCCI, A. C.B. Os nativos digitais no Brasil e seus comportamentos diante das telas. MATRIZes, v. 8, nº 1, jan/jun, 2014. 
<http://www.matrizes.usp.br/index.php/matrizes/article/view/404>. Acesso em: 15 maio 2015.

PELANDA, E.C. Comunicação móvel no contexto brasileiro. In: Lemos, André. Josgrilberg, Fábio (Orgs. ) Comunicação e mobilidade. Salvador, EDUFBA, 2009, p.11-18.

PONTES, J. P.; BROCARDO, J.; OLIVEIRA, H. Investigações matemáticas na sala de aula. Belo Horizonte: Autêntica Editora, 2013.

POSTMAN, N. Tecnopólio: a rendição da cultura à tecnologia. São Paulo: Nobel, 1994.

PRETTO, N. (Org.). Tecnologias e novas educações. Salvador: EDUFBA, 2005.

PRIMO, A. O Aspecto relacional das interações na Web 2.0. in Web 2.0: participação e vigilância na era da comunicação. Antoun (org.). Rio de Janeiro: MouadX, 2008.

RUDIGER, F. As teorias da cibercultura: pespectivas, questões e autores. Porto Alegre: Sulina, 2011.

SANTOS, E. Pesquisa - Formação na cibercultura. Whitebooks, 2014.

SCHWERTL, S.L. Educação científica e tecnológica em cursos de engenharia com apoio dos espaços sociais da Web 2.0. Tese de doutorado. UFSC, 2016.

Recebido: 08 jul. 2016.

Aprovado: $21 \mathrm{dez} .2016$.

DOI: $10.3895 /$ rbect.v9n1.4434

Como citar: SCHWERTL, S. L. LEONEL, A. A. Discussão de tópicos de Matemática Básica nos espaços sociais da Web 2.0: desafios e possibilidades a partir da análise de uma intervenção pedagógica. Revista Brasileira de Ensino de Ciência e Tecnologia, v. 9, n. 3, 2016. Disponível em:

$<$ https://periodicos.utfpr.edu.br/rbect/article/view/4434>. Acesso em: xxx.

Correspondência:

Direito autoral: Este artigo está licenciado sob os termos da Licença Creative Commons-Atribuição 4.0 Internacional. 